\title{
Relationships between Knowledge Absorptive Capacity, Innovation Performance and Information Technology. Case study: the Romanian Creative Industries SMEs
}

\author{
Doina I. POPESCU ${ }^{1 *}$, Sebastian-Ion CEPTUREANU1, Adriana ALEXANDRU², \\ Eduard-Gabriel CEPTUREANU ${ }^{1}$ \\ ${ }^{1}$ The Bucharest University of Economic Studies, Romana Square, Bucharest, 010374, Romania \\ doina.popescu@man.ase.ro (*Corresponding author), sebastian.ceptureanu@man.ase \\ eduard.ceptureanu@man.ase.ro \\ ${ }^{2}$ National Institute for Research and Development in Informatics, Averescu Bvd., Bucharest, 011455, Romania \\ adriana@ici.ro
}

\begin{abstract}
The purpose of this paper is to investigate the relationships between absorptive capacity, innovation performance and Information Technology in Romanian small and medium-sized enterprises (SMEs). This is the first study conducted in Romania which deals with concepts regarding knowledge absorptive capacity and information technology, based on such a large sample of 357 small and medium-sized enterprises from creative industries. The findings identify the effect of multiple dimensions of knowledge absorptive capacity on SMEs' innovation performance from an Information Technology perspective, offering new theoretical and pragmatic insights.
\end{abstract}

Keywords: Information Technology, absorptive capacity, innovation, knowledge integration, knowledge transfer.

\section{Introduction}

\subsection{From information to knowledge}

In recent years, the fundamental importance of knowledge to business had been highlighted by authors as Nonaka et al. (1996), Kebede (2010) and Liautaud et al. (2000). Firms are becoming more intelligent in developing, adopting and adapting disruptive technologies in their business processes, in order to increase their efficiency and innovativeness through knowledge flows and data/information gathering (Malhotra, 2000). Facing the knowledge and technologydriven contemporary economy- characterized by trends such as globalization, technological and industrial convergence- successful firms use specific mechanisms to manage knowledge (Gold et al., 2001). In fact, the widespread scholarly and applied interest in organizational knowledge has primarily addressed the issue of managing knowledge to increase organizational benefits.

IT influences the development of important organizational capabilities, such as absorptive capacity (Byrd et al., 2003). Since IT applications provide quick and easy access to external sources of knowledge and new, more intense communication channels (Corso et al. 2003), the utilization and mastery of new and advanced IT instruments will be associated with the

development of potential absorptive capacity (Daghfous, 2004). Proper use of IT can enhance potential absorptive capacity. For instance, IT is necessary to design and use advanced storage technology and sophisticated retrieval techniques (i.e. multimedia databases and expert systems) to enhance knowledge-storing capabilities (Chou, 2005; Civi, 2000). Promotion and development of IT that cover the depth and breadth of the IT technical specialties within the organization (Byrd et al., 2001) foster the creation of knowledge directories and networks (Alavi et al., 2001).

\subsection{Knowledge absorptive capacity insights}

Knowledge is described as one of the most strategically significant resources of the organization and the foundational element of valuable intangible organizational resources and capabilities (Grant, 1996; Popescu et al., 2018). Indeed, many academics argue that organizational knowledge is essential for determining competitive advantage, added value and sustainability (Conner et al., 1996). According to the knowledge-based view (KBV), the foundation of organizational performance lies in its ability to generate- 
combine-recombine-exploit knowledge (Grant, 1996). Thus, in the age of knowledge economy, knowledge, understood as a strategic resource, is essential to organizational ability to innovate and compete (Ceptureanu et al., 2017a).

Absorptive capacity, defined as "the ability of a firm to recognize the value of new, external information, assimilate it, and apply it to commercial ends" (Cohen et al., 1990, p.128), has become a classic notion of management research (Huang et al., 2015). Many previous studies have indicated that absorptive capacity contributes to organizational innovation and financial/managerial performance (Fosfuri et al., 2008; Chen, Y.S. et al., 2009; Alexandru et al., 2015; Ceptureanu et al., 2019a, b). In addition, Santangelo (2000) investigates the role of corporate technological specialization factors in the inclusion of strategic technological partnerships in the European ICT industry by carrying out a dynamic analysis considering absorptive capacity. Harrington et al. (2005) examine the role of absorptive capacity in IT implementation success. Their research provides support for the proposed dimensions of absorptive capacity and its role as an antecedent of corporate culture that acts to influence the implementation of new technologies.

Although there has been increasing growth in the literature focusing on absorptive capacity, significant disparities remain. First, few studies have focused on the relationships between the multiple dimensions of knowledge absorptive capacity and organizations' innovation performance (Flatten et al., 2011, Ceptureanu et al., 2017b). Second, only a few researches have examined a coherent theory and completed an empirical verification of the potential internal mechanisms among the multiple dimensions of knowledge absorptive capacity (Zahra et al., 2002). Thirdly, only a few studies have analyzed the connections between the above elements at the level of small and medium-sized enterprises. These gaps limit theory and practice development regarding the concept of knowledge absorptive capacity and organizational performance.

Thereby, based on the above research disparities, we analyze the relationships between multiple dimensions of knowledge absorptive capacity and organizations' innovation performance and explore mediating processes in these relationships. Our analysis is performed on small and medium-sized enterprises from Romanian creative industry. According to Davies et al. (2013), the economic activities included in the creative industries category have three characteristics: a) they are developed around human creativity; b) they are vehicles for symbolic-meaning messages beyond the economic utility; c) they show own potential property rights. Most creative sectors develop large margins of added value for products placed on the market. In this respect, issues related to innovation and knowledge-based economic growth is often highlighted (Crook et al. 2011).

Our findings contribute to absorptive capacity research by identifying the different sources of absorptive capacity. Additionally, our findings develop management theory by theoretically and empirically demonstrating how knowledge absorptive capacity affects organizations' innovation from a small and medium-sized perspective.

The remainder of this paper is organized as follows. Section 2 contains a critical overview of the relevant literature and discusses the research hypotheses; Section 3 presents data sources, research methods and constructs reliability/ validity; Section 4 provides the obtained empirical findings. Finally, in Section 6, we discuss the theoretical and practical contributions of the study and conclusions.

\section{Literature review and hypotheses}

Knowledge acquisition capability is related to organizational ability to identify and acquire externally generated knowledge important to its operations (Zahra et al., 2002). The knowledge acquisition process can be summarized as the process whereby organizations acquire relevant knowledge resources while interacting with their environments (Sherwood et al., 2008). In a dynamic environment, knowledge acquisition capability enables organizations to identify the external environment more quickly (Lei et al., 1996) and supports them in expanding the breadth and depth of available knowledge, which

https://www.sic.ici.ro 
can enhance their technical abilities (Yli-Renko et al., 2001). Previous studies have connected knowledge acquisition to organization innovation (Chen C.J. et al., 2009). Overall, external sourcing of knowledge is an essential practice for organizations to improve their innovation performance (Berchicci, 2013). ITs perform a critical role in the development and maintenance of a firm's knowledge acquisition capacity (Roberts et al. 2012), a key factor affecting the improvement of organizational performance (Kostopoulos et al. 2011). Therefore, we propose the following:

H1. Knowledge acquisition capability is positively correlated with SMEs' innovation performance.

Knowledge assimilation capability refers to organizational routines and processes that allow to analyze, interpret, and understand information obtained from external sources (Zahra et al., 2002). The ability to assimilate external knowledge can accelerate the rate of solving problems and shorten the development cycle of new products/services. Additionally, assimilating external knowledge can avoid repetitive work, update organizational knowledge reserves and enhance its innovativeness and competitiveness (Hoarau, 2014). Thus, enterprises with a stronger assimilation capability are more powerful in terms of innovation performance (Inkpen, 2000). On the other hand, if an organization does not have a strong ability to assimilate new knowledge, it will waste intellectual resources (Huber, 2001).

Therefore, we propose the following:

H2. Knowledge assimilation capability is positively correlated with SMEs' innovation performance.

Knowledge integration denotes organizational ability to develop and refine the routines which facilitate the combination of existing knowledge with newly acquired and assimilated one (Zahra et al., 2002). Effective knowledge integration will accelerate the absorption of new knowledge and realize efficient integration and innovation, likely yielding better business performance (YliRenko et al., 2001). When there are differences between new and existing knowledge, an organization cannot simply copy or immediately understand the external knowledge; therefore, organizational knowledge integration capability becomes even more necessary. Organizations can reconstruct their cognitive structure from a new perspective through knowledge integration (Todorova et al., 2007), thus enhancing their innovation performance.

Rapid advances in IT require that IT professionals update their skills continuously (Lee et al., 2010). Under these circumstances, organizations must be conscious of the relevance of this phenomenon, which is related to the increasing importance of using IT to develop interdependent tasks to foster interaction among organizational members (Griffith et al. 2003). Interaction, in turn, facilitates the capture and the application of knowledge in different contexts (Rico et al., 2005). Firms will thus be more ready to improve their potential and realized integration capacity, increasing the levels of external knowledge acquisition, assimilation, transformation, and exploitation (JiménezBarrionuevo et al., 2011).Therefore, we propose the following:

H3. Knowledge integration capability is positively correlated with SMEs'innovation performance.

Knowledge exploitation capability is related to the organizational ability to incorporate and utilize the acquired, assimilated, and transformed knowledge into their operations and routines to solve real-world problems, allowing them to create new operations and competencies, and ultimately, to translate that knowledge into profit (Mitchell, 2006). Studies have found that there is a close link between knowledge exploitation capability and organizational innovation output (Alavi et al., 2001). Thus, enterprises with a strong knowledge exploitation capability can continuously translate new and existing knowledge into innovative products and services (Alavi et al., 2001). On the other hand, organizational knowledge exploitation capability can help them in promoting their innovation outputs by improving the performance of individual creativity (Miller et al., 2007). Accordingly, organizations should augment the application of outside knowledge to achieve better innovation performance (Majchrzak et al., 2004). 
The use of IT in interdependent tasks is becoming an important building block in today's knowledgebased organizations (Rico et al., 2005). A team's ability to integrate its existing knowledge stock and apply it in a new context is a key factor in team performance (Young-Choi et al., 2010) but also affects the development of knowledge exploitation capability, which involves the transformation and exploitation of new external knowledge (Zahra et al., 2002). Teams that interact through the use of IT must not only share knowledge but also apply it effectively to address the given challenge (Young-Choi et al., 2010). Thanks to the use of IT in interdependent tasks, team members can solve complex problems and invent new solutions by considering diverse perspectives (Boland et al., 1995), improving their exploitation of knowledge. Therefore, we propose the following:

H4. Knowledge exploitation capability is positively correlated with SMEs' innovation performance.

The existing literature suggests that the four dimensions of knowledge absorptive capacity are correlated with SMEs' innovation performance (Inkpen, 2000). In practice, high levels of knowledge acquisition and knowledge assimilation do not necessarily result in better innovative output, unless, that is, the potential absorptive capacity positively influences the realized one (Leal-Rodríguez et al., 2014). Knowledge residing in this organization cannot be fully leveraged. However, the performance of the units to which knowledge is successfully transferred and applied improves significantly. Thus, in organizations' operational processes, externally acquired knowledge must go through multiple, iterative steps before organizations can exploit this knowledge to create value (Camisón et al., 2010).

We can observe that knowledge acquisition is closely linked to knowledge integration (Malik, 2013). Moreover, an organization is often understood as a knowledge-integrating institution that specializes in the transfer of knowledge (Gooderham et al., 2011). Given that the conversion of acquired knowledge can lead to new products and superior performance (Camisón et al., 2010), organizations with a positive knowledge integration capability can make external knowledge into internal knowledge, thereby effectively producing new, innovative ideas. Therefore, we propose the following:

H5(1). Knowledge integration capability mediates the relationship between knowledge acquisition and SMEs' innovation performance.

The process of knowledge acquisition largely influences organizational knowledge absorptive capacity. If there is no knowledge acquisition, any follow-up process will cease to exist. Thus, the effectiveness of knowledge exploitation depends on organizational knowledge acquisition capability. Moreover, given that the ability to exploit knowledge is a key component of innovative capabilities (Cohen et al., 1990), if an organization can acquire new knowledge and then apply that new knowledge to the production of new products and market development, it will be more successful in promoting innovation output. Therefore, we propose the following:

H5(2). Knowledge exploitation capability mediates the relationship between knowledge acquisition and SMEs' innovation performance.

Knowledge assimilation capability represents the organizational ability to absorb external knowledge (Camisón et al., 2010). Knowledge assimilation requires an understanding of how the new information corresponds to that already contained in the knowledge base and how this existing information must be modified to reflect the experts' view of the domain (Lefkowitz et al., 1988). To assimilate the knowledge and obtain advantages from it, members of organizations must interpret and comprehend such knowledge (Jiménez-Barrionuevo et al., 2011). However, after the process of knowledge assimilation, knowledge still exists as an independent body, which, standing alone does not create value for it. In this respect, the knowledge integration capability can combine new knowledge with original knowledge, creating a unified knowledge setting and, hence, achieving a process of successful innovation. Therefore, we propose the following:

H5(3). Knowledge integration capability mediates the relationship between knowledge assimilation and SMEs'innovation performance. 
Organizational knowledge exploitation capability is closely linked to the effectiveness of the organizational knowledge assimilation; a good level of knowledge assimilation capability can bring great knowledge exploitation capability. Accordingly, organizations that consistently invest in assimilating and exploiting new external knowledge are more likely to generate innovative products and better meet the needs of the marketplace (Kostopoulos et al., 2011). As Cohen et al. (1990) note, absorptive capacity refers not only to the assimilation of information and knowledge but also to the ability to exploit that information and knowledge. Therefore, for organizations that have a better knowledge exploitation capability, the internal knowledge generated by the knowledge assimilation process can form the basis for the capitalization of new knowledge, hence producing more innovation outputs. Therefore, we propose the following:

H5(4). Knowledge exploitation capability mediates the relationship between knowledge assimilation and SMEs' innovation performance.

The conceptual model of our work is shown in Figure 1.

\section{Methods and results}

\subsection{Data collection}

We collect the responses from two databases: one of National Institute of Statistics regarding creative industry sector, and one from national R\&D project (UEFISCDI, PN-IIIP1-1.2-PCCDI-2017-0800 / 86PCCDI/2018 FutureWeb). The responses from the participants were collected through an email survey, and the participation was kept voluntary with follow up emails. The measurement instrument for the survey was sent to 1241 entrepreneurs with the URL of the survey mentioned in the email. The survey period lasted for six months from $5^{\text {th }}$ of September 2018 to $23^{\text {th }}$ of February 2019.All firms have been randomly selected according to their size and 11 sub-sectors in the Romanian creative industries sector by using a stratified random sampling method. According to Romanian classification, creative industries sector is formed by NACE code (represents the Statistical classification of economic activities in the European Community) as follows: a) Code 23- ceramic articles manufacturing; b) Code 32musical/ sports/ games/jewelry manufacturing; c) Code 58- publishing activities; d) Code 59 motion pictures, video and audio recording; e) Code 60 - Radio \& TV activities; f) Code 71 architectural and engineering activities; g) Code 72- R\&D ; h) Code 73- advertising activities; i) Code 74- design activities; j) Code 90- artistic interpretation; k) Code 93-recreational activities. After the data tabulation and cleaning, 357 valid responses were obtained which were used for further analysis, yielding a response rate of $28.76 \%$ The questionnaire was developed in English language and the statements measuring all the constructs were anchored on five-point Likert scale. In our research, we use Confirmatory factor analysis (CFA). CFA is a multivariate statistical procedure that is used to test how well the measured variables represent the number of constructs (Asparuhov et al, 2009). By using this procedure, researchers can specify the number of factors required in the data and which measured variable is related to which latent variable (Jackson et al, 2009). SPSS 19 with R Integration Package add-on was used for data analysis.

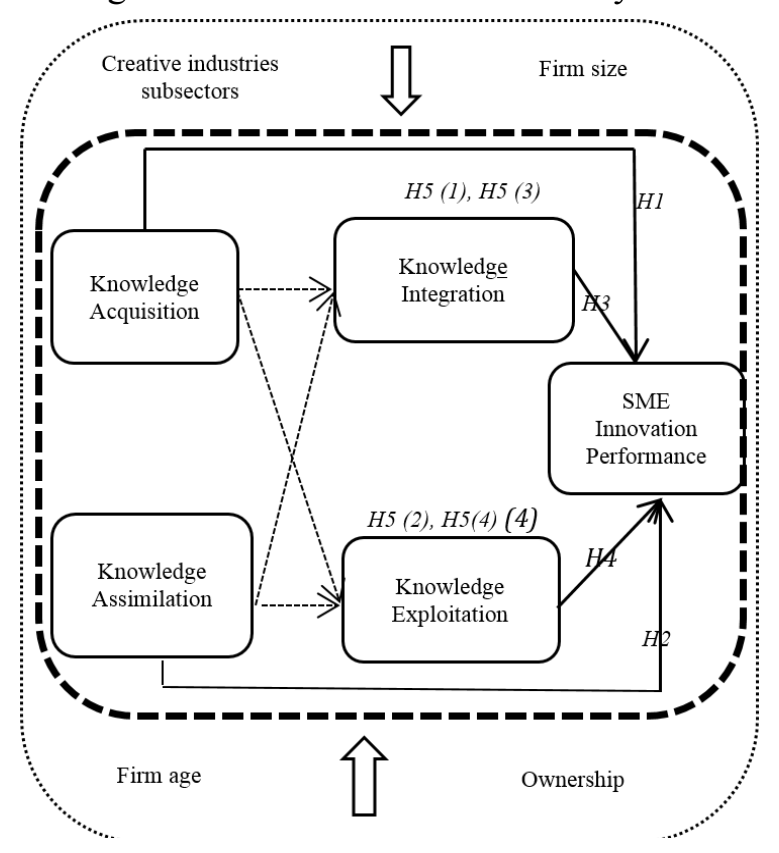

Figure 1. Conceptual model

(Note: The dashed lines denote the paths of mediating effects.) 
The results in Table 1 show the profile of the respondents. In terms of experience level, the respondents who have worked in related industries for more than six years accounted for $38.09 \%$; in terms of educational background, the respondents with undergraduate degrees or above accounted for $100 \%$; and in terms of job function, managers accounted for $69.46 \%$.

Table 2 summarizes the characteristics of the sample, including firm age (FA), total assets (TA), annual turnover (AT), ownership (OWN), firm size (FS), research and development (R\&D) expenditure intensity (R\&DEI), and $R \& D$ personnel intensity (R\&DPI). Moreover, results in Table 4 substantiate that the square roots of the AVE values in the diagonal are greater than the correlation coefficients in the same line and column, thus proving satisfactory results for discriminant validity. We use linear regression models in order to reflect the research questions that that we intend to test.
Table 1. Profile of the respondents

\begin{tabular}{|c|c|c|c|}
\hline Classification & Characteristics & Number & Percentage (\%) \\
\hline \multirow{4}{*}{$\begin{array}{l}\text { Experience } \\
\text { level (years) }\end{array}$} & $\bullet<3$ & 106 & 29.69 \\
\hline & $\bullet 3-5$ & 115 & 32.21 \\
\hline & • 6-10 & 99 & 27.73 \\
\hline & - $>10$ & 37 & 10.36 \\
\hline \multirow{2}{*}{$\begin{array}{l}\text { Educational } \\
\text { background }\end{array}$} & - Undergraduate & 249 & 69.75 \\
\hline & $\begin{array}{l}\text { - Master degree } \\
\text { or above }\end{array}$ & 108 & 30.25 \\
\hline \multirow{5}{*}{ Job function } & - Senior manager & 8 & 2.24 \\
\hline & $\begin{array}{l}\text { - Middle-level } \\
\text { manager }\end{array}$ & 119 & 33.33 \\
\hline & $\begin{array}{l}\text { - Lower-level } \\
\text { manager }\end{array}$ & 121 & 33.89 \\
\hline & - R\&D staff & 109 & 30.53 \\
\hline & Total & 357 & 100 \\
\hline
\end{tabular}

Limited liability companies (LLCs), public limited companies (PLCs), mixed enterprises (MEs), foreignfunded enterprises (FIEs).

${ }^{a}$ Number of R\&D employees/total number of employees.;

${ }^{\mathrm{b}}$ Annual R\&D expenditure/total sales.

Table 2. Characteristics of the sample.

\begin{tabular}{|c|c|c|c|}
\hline \multirow[t]{2}{*}{ Classification } & Item & Number & Percentage (\%) \\
\hline & $\bullet<3$ & 24 & 6.72 \\
\hline & • $3-5$ & 38 & 10.64 \\
\hline \multirow[t]{3}{*}{ FA (years) } & $\bullet 6-10$ & 112 & 31.37 \\
\hline & $\bullet 11-15$ & 96 & 26.89 \\
\hline & $\bullet>15$ & 87 & 24.37 \\
\hline \multirow{4}{*}{ TA (EUR) } & $\bullet<1.000 .000$ & 39 & 10.92 \\
\hline & $\bullet 1.000 .000-10.000 .000$ & 96 & 26.89 \\
\hline & $\bullet 10.000 .000-20.000 .000$ & 126 & 35.29 \\
\hline & $\bullet 20.000 .000-50.000 .000$ & 96 & 26.89 \\
\hline \multirow{4}{*}{ AT (EUR) } & $\bullet<500.000$ & 62 & 17.37 \\
\hline & • 500.000-5.000.000 & 99 & 27.73 \\
\hline & $\bullet 5.000 .000-10.000 .000$ & 119 & 33.33 \\
\hline & $\bullet 10.000 .000-43.000 .000$ & 77 & 21.57 \\
\hline \multirow{4}{*}{ OWN } & $\bullet$ LLCs & 48 & 13.45 \\
\hline & - PLCs & 24 & 6.72 \\
\hline & - Mes & 166 & 46.50 \\
\hline & - FIEs & 119 & 33.33 \\
\hline \multirow{5}{*}{$\mathrm{R} \& D E I^{a}$} & $\bullet<5 \%$ & 54 & 15.13 \\
\hline & • $5 \%-10 \%$ & 91 & 25.49 \\
\hline & $\bullet 10 \%-15 \%$ & 103 & 28.85 \\
\hline & $\bullet 15 \%-20 \%$ & 48 & 13.45 \\
\hline & $\bullet>20 \%$ & 61 & 17.09 \\
\hline \multirow{5}{*}{$\mathrm{R} \& \mathrm{DPI}{ }^{\mathrm{b}}$} & $\bullet<5 \%$ & 42 & 11.76 \\
\hline & • $5 \%-10 \%$ & 82 & 22.97 \\
\hline & $\bullet 10 \%-15 \%$ & 121 & 33.89 \\
\hline & $\bullet 15 \%-20 \%$ & 66 & 18.49 \\
\hline & $\bullet>20 \%$ & 46 & 12.89 \\
\hline \multirow{3}{*}{$\begin{array}{l}\text { Number of } \\
\text { employees } \\
\text { (Firm size) }\end{array}$} & $\bullet<9$ & 53 & 14.85 \\
\hline & - $10-49$ & 127 & 35.57 \\
\hline & • $50-249$ & 177 & 49.58 \\
\hline
\end{tabular}




\subsection{Measures}

a) Dependent variable and predictors - Following the Balanced Scorecard Institute, innovation performance is measured by using four indicators (IP1-IP4). The respondents are required to note the degree to which they agreed with various statements regarding their companies' innovation performance over the past three years when comparing it to their competitors (see Table 1).

Following the work of Zahra et al. (2002), Flatten et al. (2011) and Noblet et al. (2011), knowledge absorptive capacity is measured by four constructs and thirteen items. The respondents are required to note the degree to which they agreed with various statements regarding their companies' knowledge absorptive capability (see Table 3 ). In statistics, in order to be usefully predictive the variable must show independence. We call this a predictor or an independent variable.

Each item from Table 3 has been used in defining a question used in the questionnaire. b) Controls - We use the creative industry subsectors, firm age, ownership, and firm size as control variables. (a) Industry is a dummy variable that included 11 subsectors in the Romanian creative industries sector. (b) Firm age is measured by five ordinal variables $(1=0-3$ years; $2=3-5$ years; $3=5-10$ years; $4=10-15$ years; to $5=>15$ years). (c) Ownership is a dummy variable assessed using four types of firms: limited liability companies (LLCs), public limited companies (PLCs), mixed enterprises (MEs), and foreign-invested enterprises (FIEs). (d) Firm size is assessed using the number of employees, via three ordinal variables $(1=$ '<10'; $2=$ '10-49'; 3 $=$ '50-249').

\subsection{Reliability and validity}

We assess the reliability of the constructs using Cronbach's alpha. Cronbach's alpha is a measure of internal consistency, that is, how closely related a set of items are as a group. It is considered to be a measure of scale reliability. As illustrated

Table 3. Construct measurement and confirmatory factor analysis (CFA)

\begin{tabular}{|c|c|c|c|c|}
\hline Item description summary & $\begin{array}{c}\text { Factor } \\
\text { loadings }\end{array}$ & t-Value & AVE & CR \\
\hline \multicolumn{5}{|l|}{ Knowledge acquisition (Cronbach's $\alpha=0.659$ ) } \\
\hline $\begin{array}{l}\text { KAC1. Employees quickly identify and acquire relevant information on organizational internal } \\
\text { and external environment. }\end{array}$ & $0.766^{\star \star \star}$ & 9.114 & 0.594 & 0.813 \\
\hline KAC2. Daily motivation for employees to use creative industry information sources. & $0.800^{* \star *}$ & 7.878 & & \\
\hline $\begin{array}{l}\text { KAC3. Employees have the ability to readily capture and engage the relevant knowledge beyond } \\
\text { creative industry boundaries. }\end{array}$ & $0.745^{\star \star \star}$ & 7.520 & & \\
\hline \multicolumn{5}{|l|}{ Knowledge assimilation (Cronbach's $\alpha=0.734$ ) } \\
\hline KAS1. Employees quickly recognize shifts on the environment from the information distributed to them. & $0.754^{\star \star \star}$ & 9.059 & 0.556 & 0.831 \\
\hline $\begin{array}{l}\text { KAS2. Employees quickly understand new opportunities and threats from the information } \\
\text { distributed to them. }\end{array}$ & $0.791^{* \star *}$ & 9.169 & & \\
\hline KAS3. There is a quick information flow within the organization. & $0.735^{\star \star *}$ & 9.268 & & \\
\hline KAS4. Organization exchanges ideas through periodical meetings. & $0.694^{\star \star *}$ & 10.903 & & \\
\hline \multicolumn{5}{|l|}{ Knowledge integration (Cronbach's $\alpha=0.736$ ) } \\
\hline KI1. Employees have the ability to structure and use collected knowledge. & $0.823^{\star \star *}$ & 14.141 & 0.651 & 0.848 \\
\hline KI2. Employees can link existing knowledge with new insights. & $0.849^{* \star *}$ & 13.273 & & \\
\hline KI3. Employees are able to transform new knowledge into productivity. & $0.747^{\star \star *}$ & 10.542 & & \\
\hline \multicolumn{5}{|l|}{ Knowledge exploitation (Cronbach's $\alpha=0.730$ ) } \\
\hline KE1. Degree of existing knowledge utilization. & $0.772^{* \star *}$ & 11.063 & 0.652 & 0.844 \\
\hline KE2. Organization regularly adapts technologies in accordance with new knowledge and economy of scale. & $0.840^{* \star \star}$ & 12.901 & & \\
\hline $\begin{array}{l}\text { KE3. Organization has the ability to work more effectively by adopting new technologies and } \\
\text { economy of scale. }\end{array}$ & $0.798^{* * *}$ & 14.322 & & \\
\hline \multicolumn{5}{|l|}{ Innovation performance (Cronbach's $\alpha=0.804)$} \\
\hline IP1. A ratio of number of new ideas per 100 employees & $0.758^{\star \star \star}$ & 13.557 & 0.632 & 0.871 \\
\hline IP2. Percent of new ideas selected for funding & $0.792^{\star \star \star}$ & 11.598 & & \\
\hline IP3. A ratio of revenue from new ideas divided by the average cost of implementation & $0.811^{* * \star}$ & 11.414 & & \\
\hline IP4. Aggregate ROI of new ideas implemented & $0.814^{* * *}$ & $11.601^{* * *}$ & & \\
\hline $\begin{array}{l}\text { Model fit index } \chi^{2}=343.749, \mathrm{p}=.000 ; \chi^{2} / \mathrm{df}=3.101 ; \mathrm{GFI}=0.902 ; \mathrm{CFI}=0.895 ; \mathrm{IFI}=0.895 \text {; } \\
\text { RMSEA }=0.073\end{array}$ & & & & \\
\hline
\end{tabular}


in Table 1, the results show that the Cronbach's alpha values of the individual constructs are greater than 0.7 , indicating an acceptable level of reliability. Then, confirmatory factor analysis (CFA) is used to test the convergent validity of the constructs. Results in Table 1 show that the model fit the data well $(\chi 2=344.749, \mathrm{p}=.00$; $\chi^{2} / \mathrm{df}=3.101$, goodness-of-fit index [GFI] $=$ 0.902 , comparative fix index $[\mathrm{CFI}]=0.895$, incremental fit index [IFI] $=0.895$, and root mean square error of approximation [RMSEA] $=0.073)$, demonstrating that the model is well constructed, except for CFI (Bentler, 1990). All items loaded significantly on their corresponding latent constructs, and the construct reliability (CR) was $>0.7$, suggesting that the items in each latent variable have sufficient consistency to explain the latent variables. Furthermore, the average variance extracted (AVE) values of all variables are greater than the threshold value of 0.50 . Overall, our results provide evidence for convergent validity (Hooper et al, 2008).

\subsection{Regression results}

In our study, Ordinary Least Squares (OLS) method is used for estimating the unknown parameters. Table 4 presents the means, standard deviations, and correlation coefficients of the examined variables. Results indicate that knowledge acquisition (KAQ), knowledge assimilation (KAS), knowledge integration (KI), and knowledge exploitation (KE) are significantly correlated with SMEs' innovation performance
(IP). Table 5 highlights the regression results of the control variables, knowledge absorptive capacity and innovation performance.

Table 5. Results of OLS regression for the direct effects $^{*}$

\begin{tabular}{|c|c|c|c|c|c|}
\hline \multirow{2}{*}{ Variables } & \multicolumn{5}{|c|}{$\begin{array}{l}\text { Dependent variable (DV): } \\
\text { Innovation performance }\end{array}$} \\
\hline & $\begin{array}{c}\text { Model } \\
1\end{array}$ & $\begin{array}{c}\text { Model } \\
2\end{array}$ & $\begin{array}{c}\text { Model } \\
3\end{array}$ & $\begin{array}{c}\text { Model } \\
4\end{array}$ & $\begin{array}{c}\text { Model } \\
5\end{array}$ \\
\hline \multicolumn{6}{|c|}{ Controls 11 dummies for creative industries sector-added } \\
\hline FA & $\begin{array}{l}0.072^{* *} \\
(0.032)\end{array}$ & $\begin{array}{c}0.045 \\
(0.030)\end{array}$ & $\begin{array}{c}0.038 \\
(0.029)\end{array}$ & $\begin{array}{c}0.036 \\
(0.028)\end{array}$ & $\begin{array}{c}0.039 \\
(0.026)\end{array}$ \\
\hline OWN1 & $\begin{array}{l}-0.090 \\
(0.111)\end{array}$ & $\begin{array}{l}-0.059 \\
(0.103)\end{array}$ & $\begin{array}{c}0.030 \\
(0.102)\end{array}$ & $\begin{array}{l}-0.011 \\
(0.103)\end{array}$ & $\begin{array}{c}0.020 \\
(0.097)\end{array}$ \\
\hline OWN 2 & $\begin{array}{c}0.069 \\
(0.134)\end{array}$ & $\begin{array}{c}0.105 \\
(0.129)\end{array}$ & $\begin{array}{c}0.119 \\
(0.122)\end{array}$ & $\begin{array}{c}0.126 \\
(0.124)\end{array}$ & $\begin{array}{c}0.074 \\
(0.114)\end{array}$ \\
\hline OWN 3 & - & - & - & $\begin{array}{l}-0.025 \\
(0.072)\end{array}$ & $\begin{array}{l}-0.058 \\
(0.064)\end{array}$ \\
\hline OWN 4 & $\begin{array}{c}0.089 \\
(0.082)\end{array}$ & $\begin{array}{c}0.067 \\
(0.068)\end{array}$ & $\begin{array}{c}0.104 \\
(0.075)\end{array}$ & - & - \\
\hline FS & $\begin{array}{l}0.202^{* * *} \\
(0.052)\end{array}$ & $\begin{array}{l}0.208^{* * *} \\
(0.051)\end{array}$ & $\begin{array}{l}0.192^{* * *} \\
(0.049)\end{array}$ & $\begin{array}{l}0.203^{\text {*** }} \\
(0.047)\end{array}$ & $\begin{array}{l}0.163^{* * *} \\
(0.043)\end{array}$ \\
\hline \multicolumn{6}{|c|}{ Predictors } \\
\hline KAQ & & $\begin{array}{l}0.374^{* * *} \\
(0.056)\end{array}$ & & & \\
\hline KAS & & & $\begin{array}{l}0.471^{* * *} \\
(0.052)\end{array}$ & & \\
\hline KI & & & & $\begin{array}{l}0.537^{*+*+} \\
(0.051)\end{array}$ & \\
\hline $\mathrm{KE}$ & & & & & $\begin{array}{l}0.610^{*+* x} \\
(0.044)\end{array}$ \\
\hline $\mathrm{R}$ square & 0.130 & 0.220 & 0.273 & 0.321 & 0.393 \\
\hline $\begin{array}{l}\text { Adjusted R } \\
\text { square }\end{array}$ & 0.094 & 0.185 & 0.241 & 0.291 & 0.368 \\
\hline F-value & $3.671^{\star \star *}$ & $6.444^{* * *}$ & $8.595^{* * *}$ & $10.799^{* * *}$ & $14.889^{* * *}$ \\
\hline $\begin{array}{l}\text { Durbin- } \\
\text { Watson }\end{array}$ & 2.081 & 2.070 & 1.988 & 2.025 & 2.022 \\
\hline
\end{tabular}

$\mathrm{N}=357$; Standard errors in parentheses. For Models 1-3, the excluded variable is 'OWN 3'; For Models $4-5$, the excluded variable is 'OWN 4'. ${ }^{*} \mathrm{p}<.1$. ; ${ }^{\star \star} \mathrm{p}<.05$. ; ${ }^{\star \star *} \mathrm{p}<.01$.

Table 4. Results of correlation analysis

\begin{tabular}{|c|c|c|c|c|c|c|c|c|c|c|c|}
\hline Variables & (1) & (2) & (3) & (4) & (5) & (6) & (7) & (8) & (9) & (10) & (11) \\
\hline (1) FA & 1.000 & & & & & & & & & & \\
\hline (2) OWN 1 & $0.212^{\star \star}$ & 1.000 & & & & & & & & & \\
\hline (3) OWN 2 & 0.002 & -0.114 * & 1.000 & & & & & & & & \\
\hline (4) OWN 3 & $-0.214^{* *}$ & $-0.366^{* *}$ & $-0.263^{\star \star}$ & 1.000 & & & & & & & \\
\hline (5) OWN 4 & 0.068 & $-0.279^{* *}$ & $-0.202^{\star *}$ & $-0.634^{* *}$ & 1.000 & & & & & & \\
\hline (6) FS & $0.441^{* *}$ & $0.127 *$ & 0.023 & $-0.281^{\star *}$ & 0.187 ** & 1.000 & & & & & \\
\hline (7) KAQ & $0.141^{\star \star}$ & -0.010 & -0.053 & -0.021 & 0.064 & 0.047 & 0.771 & & & & \\
\hline (8) KAS & $0.122^{*}$ & -0.102 * & -0.030 & 0.052 & 0.039 & 0.051 & $0.542^{* *}$ & 0.743 & & & \\
\hline (9) KI & $0.107^{\star}$ & -0.089 & -0.087 & -0.023 & $0.145^{\star *}$ & 0.039 & $0.551^{* *}$ & $0.590^{* *}$ & 0.807 & & \\
\hline (10) KE & $0.109^{\star}$ & $-0.133^{* *}$ & -0.042 & 0.007 & $0.114^{*}$ & 0.096 & $0.491^{* *}$ & $0.621^{* *}$ & $0.632^{\star *}$ & 0.803 & \\
\hline (11) IP & $0.229^{* \star}$ & -0.017 & 0.024 & $-0.122^{*}$ & $0.129^{\star}$ & $0.277^{\star \star}$ & $0.344^{* *}$ & $0.415^{\star *}$ & $0.471^{* *}$ & $0.562^{\star *}$ & 0.798 \\
\hline Means & 3.488 & 0.136 & 0.078 & 0.43 & 0.328 & 2.328 & 3.743 & 3.817 & 3.814 & 3.907 & 3.557 \\
\hline S.D. & 1.181 & 0.345 & 0.268 & 0.497 & 0.464 & 0.729 & 0.581 & 0.581 & 0.603 & 0.620 & 0.709 \\
\hline
\end{tabular}

11 dummies for creative sectors are not reported here. The values of the diagonal (in bold) are the square root of the AVE (average variance extracted) values. ${ }^{* *} \mathrm{p}<.01$ level; ${ }^{*} \mathrm{p}<.05$ level (two-tailed). 
Table 6. Results of OLS regression for the mediating effects

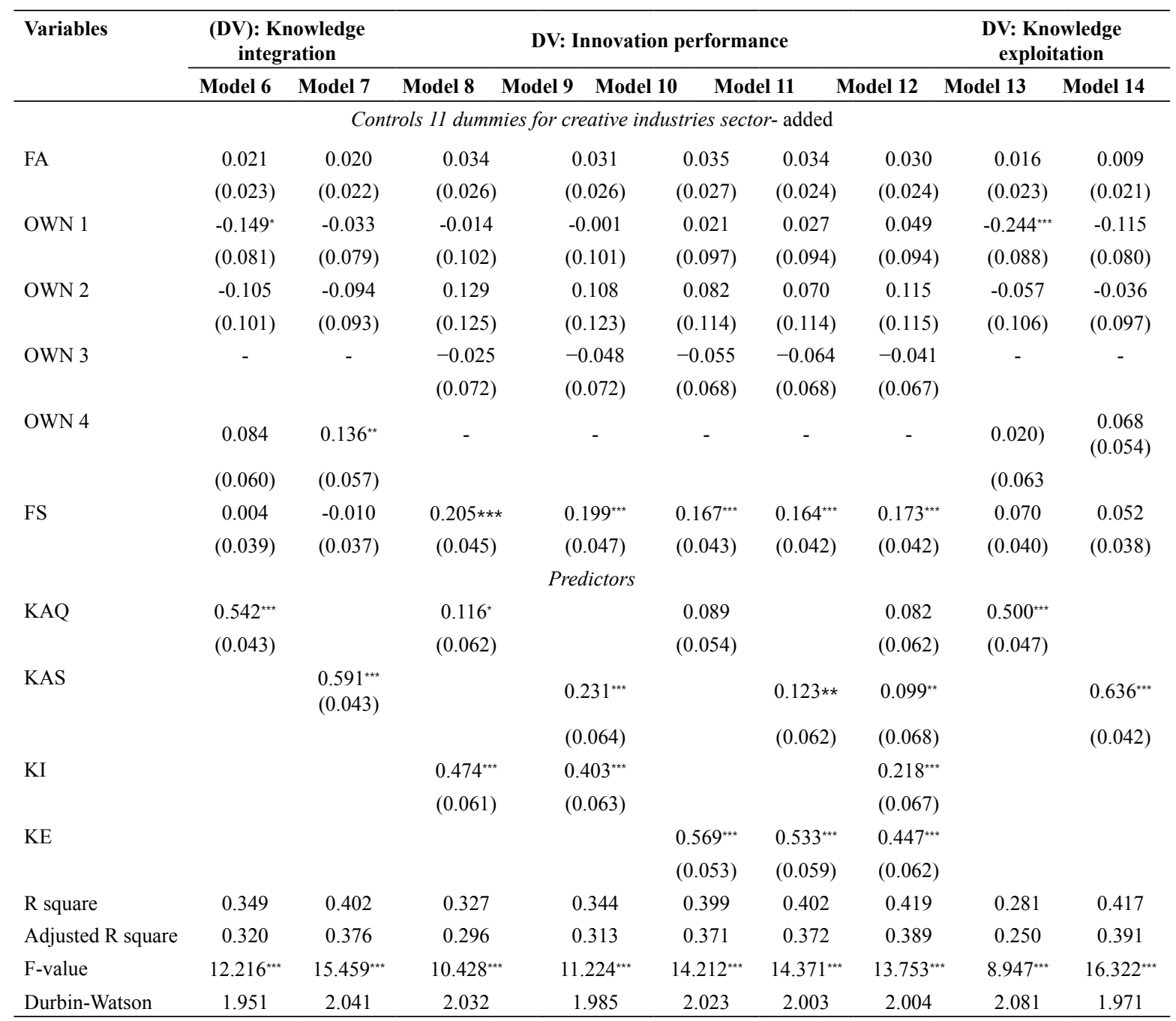

$\mathrm{N}=357$; Standard errors in parentheses. For Models 1- 2 and Models 13- 14, the excluded variable is 'OWN 3'; For Models $8-12$, the excluded variable is 'OWN 4'. ${ }^{*} \mathrm{p}<.1$. ; ${ }^{* *} \mathrm{p}<.05$. ${ }^{* * *} \mathrm{p}<.01$.

Table 6 presents the regression results for the mediating effects. These include the mediating effects of the Baron et al. (1986) three-step test, which have been long used in social/behavioral research.

\section{Discussion and conclusions}

Absorptive capacity has been recognized as a significant driver of SMEs' innovation performance (Marco, 2015). Based on our survey data from 357 SMEs in the Romanian creative industries sector, we find that there are positive relationships between dimensions of knowledge absorptive capacity and SMEs' innovation performance. Our findings confirm that organizational absorptive capability has a positive influence on its innovation performance (Kostopoulos et al., 2011). Furthermore, it confirms that both organizations' knowledge integration capability and knowledge exploitation capability mediate the connections between knowledge acquisition and organizations' innovation performance, as well as between knowledge assimilation and organizations' innovation performance.

In the context of the above-mentioned results, Table 7 presents the hypotheses accepted after data analysis.

Table 7. Hypotheses accepted after data analysis.

\begin{tabular}{|l|c|c|c|}
\hline Hypotheses & Path Coefficient & Significance & Status \\
\hline H1. & 0.374 & $p<.01$ & Supported \\
\hline H2. & 0.471 & $p<.01$ & Supported \\
\hline H3. & 0.537 & $p<.01$ & Supported \\
\hline H4. & 0.610 & $p<.01$ & Supported \\
\hline H5(1). & 0.116 & $p<.01$ & Supported \\
\hline H5(2). & 0.569 & $p<.01$ & Supported \\
\hline H5(3). & 0.231 & $p<.01$ & Supported \\
\hline H5(4). & 0.123 & $p<.01$ & Supported \\
\hline
\end{tabular}


In the future, we can expand the study by using IT for measuring absorptive capacity. For instance, Boynton et al. (1994) measured two related constructs- managerial IT knowledge and the IT management process. The integration of knowledge structures and processes had enhanced the organization's ability to assimilate and apply new knowledge. Important variables for measuring it included market knowledge creation or success in using IT.

Our research has certain limitations, which could provide inspiration for future research. First, our findings have been derived from survey data collected from SMEs in the Romanian creative industries sector, and hence, they might be different in terms of firm size, industry and country specifics.

Second, we have examined the mediating roles of knowledge integration and knowledge exploitation in the connections between knowledge acquisition

\section{REFERENCES}

1. Alavi, M. \& Leidner, D. E. (2001). Review: Knowledge management and knowledge management systems: Conceptual foundations and research issues, MIS Quarterly, 25(1), 107-136.

2. Alexandru, A., Tirziu, E., Tudora, E. \& Bica, O. (2015). Enhanced Education by Using Intelligent Agents in Multi-Agent Adaptive e-Learning Systems, Studies in Informatics and Control, 24(1), 13-22. DOI: 10.24846/ v24i1y201502

3. Asparouhov, T. \& Muthén, B. (2009). Exploratory structural equation modeling, Structural Equation Modeling, 16(3), 397-438.

4. Baron, R. M. \& Kenny, D. A. (1986). The moderator-mediator variable distinction in social psychological research: Conceptual, strategic, and statistical considerations, Journal of Personality and Social Psychology, 51(6), 1173-1182.

5. Bentler, P. M. (1990). Comparative fit indexes in structural models, Psychological Bulletin, 107(2), 238-246. and SMEs' innovation performance, as well as between knowledge assimilation and SMEs' innovation performance. However, there might be other factors that could influence such a relationship. Future research could address other potential factors to further explore this topic.

Overall, our findings provide new insights by theoretically and empirically examining the mediating processes of the connections between the multiple dimensions of knowledge absorptive capacity and SMEs' innovation performance. We consider that the generalization of our findings to other economies would be an interesting path to pursue in future research.

\section{Acknowledgement}

This work was supported by a grant of the Romanian Ministry of Research and Innovation, UEFISCDI, project number PN-III-P1-1.2PCCDI-2017-0800 / 86PCCDI/2018 - FutureWeb, within PNCDI III.

6. Berchicci, L. (2013). Towards an open R\&D system: Internal $R \& D$ investment, external knowledge acquisition and innovative performance, Research Policy, 42(1), 117-127.

7. Boland, R. J. \& Tenkasi. R.V. (1995). Perspective making and perspective taking in communities of knowing, Organization Science, 6(4), 350-372.

8. Bolívar-Ramos, M. T., García-Morales, V. J. \& Martín-Rojas, R. (2013). The effects of Information Technology on absorptive capacity and organisational performance, Technology Analysis \& Strategic Management, 25(8), 905-922.

9. Byrd, T. A. \& Davidson, N. W. (2003). Examining possible antecedents of IT impact on the supply chain and its effect on firm performance, Information \& Management, 41(2), 243-55.

10. Byrd, T. A. \& Turner, D. E. (2001). An exploratory analysis of the value of the skills of IT personnel: Their relationship to IS infrastructure and competitive advantage, Decision Sciences, 32(1), 21-47. 
11. Camisón, C. \& Forés, B. (2010). Knowledge absorptive capacity: New insights for its conceptualization and measurement, Journal of Business Research, 63(7), 707-715.

12. Ceptureanu, E. G., Ceptureanu, S. I., Popescu, D. I. \& Vlad, L. B. (2017a). Two stage analysis of successful change implementation of knowledge management strategies in energies companies from Romania, Energies, 10(12), 1965.

13. Ceptureanu, E. G. \& Ceptureanu, S. I. (2019a). The impact of adoptive management innovations on mediumsized enterprises from a dynamic capability perspective, Technology Analysis \& Strategic Management, 31(10), 1137-1151. DOI:10.1080/ 09537325.2019.1587160.

14. Ceptureanu, E. G., Ceptureanu, S. I \& Herteliu, C. (2019b). Evidence regarding external financing in manufacturing MSEs using partial least squares regression, Annals of Operations Research, DOI: 10.1007/ s10479-019-03291-2.

15. Ceptureanu, S. I., Ceptureanu, E. G. \& Visileanu, E. (2017b). Comparative analysis of small and medium enterprises organizational performance in clothing industry, Industria Textila, 68(2), 156-162.

16. Chen, C. J. \& Huang, J. W. (2009). Strategic human resource practices and innovation performance- The mediating role of knowledge management capacity, Journal of Business Research, 62(1), 104-114.

17. Chen, Y. S., Lin, M. J. J. \& Chang, C. H. (2009). The positive effects of relationship learning and absorptive capacity on innovation performance and competitive advantage in industrial markets, Industrial Marketing Management, 38(2), 152-158.

18. Chou, S. W. (2005). Knowledge creation: Absorptive capacity, organizational mechanisms, and knowledge storage/ retrieval capabilities, Journal of Information Science, 31(6), 453-465.

19. Civi, E. (2000). Knowledge management as a competitive asset: A review, Marketing Intelligence \& Planning, 18(4), 166-174.

20. Cohen, W. M. \& Levinthal, D. A. (1990). Absorptive capacity: A new perspective on learning and innovation, Administrative Science Quarterly, 35(1), 128-152.
21. Conner, K. R. \& Prahalad, C. K. (1996). A Resource- Based Theory of the Firm: Knowledge Versus Opportunism, Organization Science, 7(5), 477-501.

22. Corso, M., Martini, A., Pellegrini, L. \& Paolucci. E. (2003). Technological and organizational tools for knowledge management: In search of configurations, Small Business Economics, 21(4), 397-408.

23. Crook, P. \& De Propis, L. (2011). A policy agenda for EU smart growth: the role of creative and cultural industries, Policy Studies, 32(4), 365-375.

24. Daghfous, A. (2004). Absorptive capacity and the implementation of knowledge-intensive best practices, SAM Advanced Management Journal, 69(2), 21-27.

25. Davies, R. \& Sigthorsson, G. (2013), Introducing the Creative Industries. From Theory to Practice. Sage Publications.

26. Flatten, T. C., Engelen, A., Zahra, S. A. \& Brettel, M. (2011). A measure of absorptive capacity: Scale development and validation, European Management Journal, 29(2), 98-116.

27. Fosfuri, A. \& Tribó, J. A. (2008). Exploring the antecedents of potential absorptive capacity and its impact on innovation performance, Omega, 36(2), 173-187.

28. Gold, A. H., Malhotra, A. \& Segars, A. H. (2001). Knowledge management: an organizational capabilities perspective, Journal of Management Information Systems, 18(1), 185-214.

29. Gooderham, P., Minbaeva, D. B. \& Pedersen, T. (2011). Governance mechanisms for the promotion of social capital for knowledge transfer in multinational corporations, Journal of Management Studies, 48(1), 123-150.

30. Grant, R. M. (1996). Toward a knowledgebased theory of the firm, Strategic Management Journal, 17(S2), 109-122.

31. Griffith, T. L., Sawyer, J. E. \& Neale, M. A. (2003). Virtualness and knowledge in teams: Managing the love triangle of organizations, individuals, and information technology, MIS Quarterly, 27(2), 265-288.

32. Harrington, S. J. \& Guimaraes, T. (2005). Corporate culture, absorptive capacity and IT success, Information and Organization 15(1), 39-63. 
33. Hoarau, H. (2014). Knowledge acquisition and assimilation in tourism-innovation processes, Scandinavian Journal of Hospitality and Tourism, 14(2), 135-151.

34. Hooper, D., Coughlan, J. \& Mullen, M. R. (2008). Structural equation modelling: Guidelines for determining model fit. Journal of Business Research Methods, 6(1), 53-60.

35. <http://www.aippimm.ro/articol/programe/ start-up-nation-2017/start-up-nation-2017>.

36. <http://www.balancedscorecard.org/ portals/0/pdf/HowToMeasureInnovation. pdf $>$.

37. Huang, K. F., Lin, K. H., Wu, L. Y. \& Yu, P. H. (2015), Absorptive capacity and autonomous R\&D climate roles in firm innovation, Journal of Business Research, 68(1), 87-94.

38. Huber, G. P. (2001). Transfer of knowledge in knowledge management systems: Unexplored issues and suggested studies, European Journal of Information Systems, 10(2), 72-79.

39. Inkpen, A. C. (2000). Learning through joint ventures: A framework of knowledge acquisition, Journal of Management Studies, 37(7), 1019-1044.

40. Jackson, D. L., Gillaspy, J. A. \& PurcStephenson, R. (2009). Reporting practices in confirmatory factor analysis: An overview and some recommendations, Psychological Methods, 14(1), 6-23.

41. Jiménez-Barrionuevo, M. M., GarcíaMorales, V. J. \& Molina, L. M. (2011). Validation of an instrument to measure absorptive capacity, Technovation, 31(5), 190-202.

42. Kebede, G. (2010). Knowledge management: An information science perspective, International Journal of Information Management, 30(5), 416-424.

43. Kostopoulos, K., Papalexandris, A., Papachroni, M. \& Ioannou, G. (2011). Absorptive capacity, innovation, and financial performance, Journal of Business Research, 64(12), 1335-1343.

44. Leal-Rodríguez, A. L., Ariza-Montes, J. A., Roldán, J. L. \& Leal-Millán, A. G. (2014). Absorptive capacity, innovation and cultural barriers: A conditional mediation model., Journal of Business Research, 67(5), 763-768.

45. Lee, K. \& Mirchandani. D. (2010). Dynamics of the importance of IS/IT skills, Journal of Computer Information Systems, 50(4), 67-78.

46. Lefkowitz, L. S. \& Lesser, V. R. (1988). Knowledge acquisition as knowledge assimilation, International Journal of ManMachine Studies, 29(2), 215-226.

47. Lei, D., Hitt, M. A. \& Bettis, R. (1996), Dynamic core competences through metalearning and strategic context, Journal of Management, 22(4), 549-569.

48. Liautaud, B. \& Hammond, M. (2000). e-Business Intelligence: Turning Information into Knowledge into Profit. McGraw-Hill, Inc.

49. Majchrzak, A., Cooper, L. P. \& Neece, O. E. (2004). Knowledge reuse for innovation, Management Science, 50(2), 174-188.

50. Malhotra, Y. (2000). Knowledge management for e-business performance: advancing information strategy to "Internet time", Information Strategy: The Executive's Journal, 16(4), 5-16.

51. Malik, T. H. (2013). National institutional differences and cross-border universityindustry knowledge transfer, Research Policy, 42(3), 776-787.

52. Marco, T. (2015). The social underpinnings of absorptive capacity: The moderating effects of structural holes on innovation generation based on external knowledge, Strategic Management Journal, 36(4), 586-597.

53. Miller, D. J., Fern, M. J. \& Cardinal, L. B. (2007). The use of knowledge for technological innovation within diversified firms, Academy of Management Journal, 50(2), 307-325.

54. Mitchell, V. L. (2006). Knowledge integration and information technology project performance, MIS Quarterly, 30(4), 919-939.

55. Noblet, J. P., Simon, E. \& Parent, R. (2011). Absorptive capacity: A proposed operationalization, Knowledge Management Research \& Practice, 9(4), 367-377. 
56. Nonaka, I., Umemoto, K. \& Senoo, D. (1996). From information processing to knowledge creation: a paradigm shift in business management, Technology in Society, 18(2), 203-218.

57. Popescu, D. I., Alexandru, A., Ceptureanu, S. I. \& Ceptureanu, E. G. (2018). Analysis of MSEs in ICT Domain from Bucharest - Ilfov County by Using Nonaka - Takeuchi Model, Studies in Informatics and Control, 27(1), 107-116. DOI: 10.24846/v27i1y201811

58. Rico, R. \& Cohen, R. G. (2005). Effects of task interdependence and type of communication on performance, Journal of Managerial Psychology, 20(3-4), 261-274.

59. Roberts, N., Galluch, P. S., Dinger, M. \& Grover, V. (2012). Absorptive capacity and information systems research: Review, synthesis, and directions for future research, MIS Quarterly, 36(2), 625-648.

60. Santangelo, G. D. (2000). Corporate strategic technological partnerships in the European information and communications technology industry, Research Policy, 29(9), 1015- 1031.
61. Sherwood, A. L. \& Covin, J. G. (2008). Knowledge acquisition in universityindustry alliances: An empirical investigation from a learning theory perspective, Journal of Product Innovation Management, 25(2), 162-179.

62. Todorova, G. \&Durisin, B. (2007).Absorptive capacity: Valuing a reconceptualization, Academy of Management Review, 32(3), 774-786.

63. Yli-Renko, H., Autio, E. \& Sapienza, H. J. (2001). Social capital, knowledge acquisition, and knowledge exploitation in young technology-based firms, Strategic Management Journal, 22(6-7), 587-613.

64. Young-Choi, S., Lee, H. \& Yoo, Y. (2010). The impact of information technology and transactive memory systems on knowledge sharing, application, and team performance: A field study, MIS Quarterly, 34(4), 833-854.

65. Zahra, S. A. \& George, G. (2002). Absorptive capacity: A review, reconceptualization, and extension, Academy of Management Review, 27(2), 185-203. 
